\title{
6. The Political and Security Committee: practices and persuasion
}

\author{
August Danielson
}

\section{BACKGROUND TO THE POLITICAL AND SECURITY COMMITTEE}

Established with the explicit intent of making it the linchpin of European Union (EU) foreign and security policy, the Political and Security Committee (PSC) has become the primary, and arguably the most influential, preparatory body of the Common Foreign and Security Policy (CFSP) as well as the Common Security and Defence Policy (CSDP) since its establishment at the Helsinki European Council meeting in December 1999. Over the last two decades, the PSC (Comité politique et de sécurité, COPS, in French) has garnered a reputation as being a relatively hidden, yet highly effective cog in the CFSP machinery. Dubbed early on as the 'workhorse' of EU foreign and security policy (Meyer, 2006), it has gained attention not only for its key role in coordinating policy, but also for its similarity to a 'government in the shadow' (Juncos and Reynolds, 2007, p. 143). Rather than being representatives who simply negotiate fixed national preferences, the PSC members have transformed the PSC into an institution that has the capacity to influence, and at times even define, the national interests of states they represent (Howorth, 2012a, p. 447). This capacity is mainly due to the relatively large amount of leeway that the members of the PSC are given to interpret the instructions sent from their ministries of foreign affairs (MFA) (Howorth, 2012a; Juncos and Reynolds, 2007, p. 140).

Of course, the representatives' ability to influence their states' positions is not unlimited: the more salient an issue is for a member state, the more difficult it becomes for PSC members to convince their capitals to change positions. However, since such entrenched national positions are known beforehand by both the European External Action Service (EEAS) secretariat and the other member states, proposals that clearly go against the desires of a member state are often tabled by the committee chair. Therefore, the PSC has been described 
as both the 'script writer' and 'the de facto central agency for the definition and implementation of EU security policy' (Howorth, 2012b, p. 10).

The PSC has gained this crucial role because it was originally set up as a forum for consultation and information-gathering with the intent of identifying consensus positions beyond the lowest common denominator of the member states' national preferences (Bickerton, 2011, p. 179). As a consequence, member states are not only untroubled by the fact that their representatives over time 'go native' and become 'Brusselized', but also seemingly prefer that they do so (Allen, 1998; Bickerton, 2011). Although member states prefer that their own positions influence EU policy, there is a general understanding that the whole is greater than the sum of its parts, and consequentially, that compromise is needed to make both the CFSP and CSDP 'work' (Howorth, 2012 b, p. 10). In this sense, the PSC should be conceptualized not only as a committee with the intent of finding consensus, but also as a mechanism for genuinely forging consensus among representatives and, by extension, the 27 member states of the EU.

This chapter describes how this mechanism for consensus-seeking works in practice by focusing on the development of the PSC and its relationship to other bodies within the CFSP machinery, as well as by focusing on the characteristics that define the contemporary practices and processes of socialization and persuasion that exist within the group. This analysis is based on 25 interviews with representatives and deputy representatives to the PSC conducted between October 2016 and May 2019. ${ }^{1}$ The chapter first outlines the PSC's position in the CFSP decision-making process and hierarchy, as well as its relations to other institutions and committees. The following section sets up the analysis of the group's practices by describing how we should understand the role of reflexivity in a community of practice. The chapter then examines the informal practices of the PSC and the ways in which the committee works to forge consensus, followed by some concluding remarks.

\section{THE POLITICAL AND SECURITY COMMITTEE IN PERSPECTIVE}

The PSC should primarily be understood on the basis of its members: the 27 permanent representatives who negotiate and make compromises on behalf of their member states. These representatives usually serve in Brussels for several years and are often senior diplomats with substantial work experience in both national ministries of foreign affairs (MFAs) and other international

1 An anonymized list of respondents and a discussion on the chosen interview method can be found in Appendix 3 and Appendix 1, respectively. 
Table 6.1 Descriptive statistics of PSC representatives 2003-2018

\begin{tabular}{|c|c|c|c|c|c|}
\hline \multirow[t]{2}{*}{ Year } & \multicolumn{2}{|c|}{$\begin{array}{l}\text { Experience with negotiations } \\
\text { in Brussels }\end{array}$} & \multicolumn{2}{|c|}{ Share of male representatives } & \multirow{2}{*}{$\begin{array}{l}\text { Number of } \\
\text { member states }\end{array}$} \\
\hline & Mean (years) & $\mathrm{N}$ & $\%$ & $\mathrm{~N}$ & \\
\hline 2003 & $\mathrm{n} / \mathrm{a}$ & $\mathrm{n} / \mathrm{a}$ & 85.7 & 14 & 15 \\
\hline 2006 & $\mathrm{n} / \mathrm{a}$ & $\mathrm{n} / \mathrm{a}$ & 100 & 13 & 25 \\
\hline 2009 & 4.1 & 23 & 77.8 & 27 & 27 \\
\hline 2012 & 5.3 & 25 & 66.7 & 27 & 27 \\
\hline 2015 & 4.9 & 24 & 67.9 & 28 & 28 \\
\hline 2018 & 4.2 & 24 & 75.0 & 28 & 28 \\
\hline All & 4.6 & 96 & 75.9 & 137 & \\
\hline
\end{tabular}

Notes: The number of missing values for the gender variable was 1 for 2003 and 12 for 2006 . Data are from the Negotiations in the Council of the European Union (NCEU) dataset (Naurin et al., 2020). A description of the dataset can be found in Appendix 1, and the codebook describing the variables can be found at https://snd.gu.se/en/catalogue/study/snd1143.

organizations. Their seniority is indicated by the fact they are given the rank of ambassadors (Juncos and Reynolds, 2007, p. 134), a title that otherwise is given only to national representatives serving on the Committee of Permanent Representatives, Coreper I and Coreper II. In addition, PSC ambassadors have on average 4.6 years of experience of negotiating on behalf of their member states in Brussels (Table 6.1). ${ }^{2}$ Although the majority of the PSC representatives have historically been men, recently the number of female ambassadors has grown and subsequently an informal group - the 'PSC Ladies' - has met semi-regularly for lunches and dinners. A similar informal group, \#PSCRunners, is a group of ambassadors who often post photographs of their runs on Twitter when the PSC goes on field trips or travels to informal Foreign Affairs Council (FAC) ${ }^{3}$ meetings outside of Brussels (Gymnich meetings). ${ }^{4}$ In contrast to the relatively large role that the PSC has in the CFSP machinery, the formal legal text that regulates the committee's operations is only 170 words (Box 6.1). In Article 38 of the Treaty on European Union (TEU), the

2 See Chapter 5 for a comparison of the PMG and the PSC in terms of their representatives' average experience in Brussels.

3 The FAC is the council configuration for the EU member states' ministers for foreign affairs, defence, trade and development. Usually, it is the ministers of foreign affairs who meet (once a month), but ministers for defence, trade, and development also have one formal and one informal meeting per presidency (that is, once every six months).

4 A similar informal running group, consisting of the Permanent Representatives to the United Nations, has existed for roughly the same length of time (see Gladstone, 2018). 
PSC is delegated four main tasks: to monitor the international situation in the areas of the CFSP; to contribute to the definition of policies to the Council; to monitor the implementation of those policies; and to exercise the political control and strategic direction of crisis management operations. The control over EU crisis management operations usually entails oversight through yearly strategic reviews of the operations' mandates and adopting different guiding documents that detail how the EU should assess a given crisis from a political and military perspective (Crisis Management Concept, or CMC). In addition, when needed, the PSC is charged with planning and executing a crisis management operation, and does so by drafting both a Concept of Operations (CONOPS) and an Operation Plan (OPLAN).

\section{BOX 6.1 ARTICLE 38 TREATY ON EUROPEAN UNION}

Article 38 (ex Article 25 TEU)

Without prejudice to Article 240 of the Treaty on the Functioning of the European Union, a Political and Security Committee shall monitor the international situation in the areas covered by the common foreign and security policy and contribute to the definition of policies by delivering opinions to the Council at the request of the Council or of the High Representative of the Union for Foreign Affairs and Security Policy or on its own initiative. It shall also monitor the implementation of agreed policies, without prejudice to the powers of the High Representative.

Within the scope of this Chapter, the Political and Security Committee shall exercise, under the responsibility of the Council and of the High Representative, the political control and strategic direction of the crisis management operations referred to in Article 43.

The Council may authorise the Committee, for the purpose and for the duration of a crisis management operation, as determined by the Council, to take the relevant decisions concerning the political control and strategic direction of the operation.

In the day-to-day work of the PSC, the members mostly prepare decisions for the monthly FAC meeting by bridging the gaps on issues that lower-ranking Council Working Groups (CWGs) were unable to solve. Some of the more active CFSP/CSDP CWGs include the Politico-Military Group (PMG), the Working Party on Eastern Europe and Central Asia (COEST), the Africa Working Party (COAFR), the Working Party on Human Rights (COHOM), and the Working Party of Foreign Relations Counsellors (RELEX). In total, there are roughly 30 Council Working Groups that are specifically working 
on foreign affairs issues and that prepare the decisions taken in the PSC, ${ }^{5}$ although how often these meet varies (the CWGs are described in greater detail in Chapter 5).

Although each CFSP working group addresses a specific region or horizontal issue, such as Eastern Europe or human rights, the PSC is responsible for all regions and issues related to the EU's external action, resulting in a very large and broad portfolio that has steadily increased over the last decade (PSC 4, 13, 20, 25). Naturally, this increase in duties has also increased the ambassadors' workload, a development that makes it challenging for ambassadors to credibly understand all topics, and ultimately makes it difficult for them to argue their member states' positions (PSC 23). As a result, some representatives become the in-group expert on a certain topic or theme, a reputation that they can wield to influence the group's majority position (PSC 13, 23). In general, presenting facts to support an argument is perceived as a fundamental way to gain influence in the group (PSC 14, 15, 21, 23, 25).

\section{The Influence of the PSC Chair}

Normally, the PSC convenes twice a week, on Tuesdays and Thursdays, in one of the meeting rooms in the Justus Lipsius building in Brussels. However, during the week before an FAC meeting, both the number and length of meetings may increase significantly to ensure consensus is reached on the issues still left on the table. Often, the PSC chair will instruct the members to stay in the room - often a poorly ventilated room (room 50.4) - until they reach a consensus (PSC 15, 20). ${ }^{6}$ In addition to dictating the physical location of the meeting and the goal of the meeting (that is, to arrive at consensus), the PSC chair sets the agenda of the meeting, summarizes the representatives' discussions, and plays a significant role in identifying common positions among the member states; all conditions that enable consensus to be forged.

Before the Lisbon Treaty entered in force in 2009, the PSC was chaired by a representative from the rotating Council Presidency, which was also the case

\footnotetext{
5 For a complete list of the current CFSP CWGs, see https://data.consilium.europa .eu/doc/document/ST-5020-2021-INIT/en/pdf.

6 "When there are difficult points on the agenda we are put into a small room so conditions are created which are such that we want to leave the room as soon as possible ... We perceive all this as very deliberate. But we don't know. Maybe we just make fun of the EEAS and our perception that they are trying to manipulate us. We definitely see a pattern. Especially when we are put in 50.4, which is a very small room with little air and only plus one seat. It is very small. And soon there is no air and you feel really squeezed in and no one feels comfortable to sit at the table and they want to leave. So I think until three months ago they stopped putting us in that room. Too many ambassadors complained." (PSC 15)
} 
for all CFSP working groups. Given that the rotating presidency only lasts for six months, this role was previously not as significant as it is today; or at least mattered in a different way as the perceived quality of the chairs varied significantly (PSC 20). However, since 2009, the PSC has been permanently chaired by a representative from the EEAS, which has increased the role of the chair in the decision-making process. ${ }^{7}$ Over the past decade, there have been three permanent chairs, all of whom had previously served as their member state's representative to the committee: Olof Skoog (2010-2013), Walter Stevens (2013-2018) and Sofie From-Emmesberger (2018-). The respondents continuously emphasized that the actions and personality of the PSC chair were crucial components in forging consensus in the committee (PSC 16, 17, 20):

I think the importance of the personality of the chair is enormous because you can steer the discussions. You can say, you know, 'I have heard this and this I would like now that only those who cannot agree intervene', instead of letting everyone talk for one hour and then sum up. I think that the working methods of the chair are really important for the PSC. Because in Coreper, this [talking for an hour] would never happen. (PSC 16)

\section{The PSC's Relation to the EEAS and the HR/VP}

Another important aspect of the PSC is its relation to other institutions and committees, primarily the geographical and thematic CFSP CWGs, the FAC, the EEAS and Coreper II. The PSC's relationships to the CWGs and the FAC are primarily characterized by the hierarchical relationship between the levels. First, the CWGs prepare the discussions and try to solve as many issues as possible before raising the remaining points to the PSC. If the PSC cannot reach consensus, the outstanding issues are sent to Coreper II for another round of negotiations. If consensus is still not achieved, they are sent to the foreign ministers in the FAC (Bickerton, 2011, p. 180). It has been estimated that roughly 40-45 per cent of the issues discussed within the CFSP are solved on the CWG level and 15-20 per cent on the PSC and Coreper II level. That is, the foreign ministers are not involved in roughly two-thirds of all CFSP decisions, except in the formal sense, as the Council must make decisions identified as 'A-items', even without debate (Chelotti, 2014b, p. 192; Juncos

7 As the head of the EEAS, it is officially the High Representative of the Union for Foreign Affairs and Security Policy and Vice-President of the European Commission (HR/VP) who oversees the PSC and therefore has the right to chair the committee. However, now it is very rare for the HR/VP to chair the PSC meetings. According to the respondents, Javier Solana interacted with the PSC on a daily basis, whereas Catherine Ashton usually chaired the meetings twice per semester. During her spell as HR/VP, Federica Mogherini chaired the meetings roughly once per year (PSC 17). 
and Pomorska, 2011). Although some issues are simply too politically sensitive for member state representatives to find consensus in the lower levels of the decision-making process, there is a general sentiment that the CWGs, the PSC and Coreper II should do what they can to settle issues before they reach the FAC, if for no other reason than the fact that agendas of the FAC meetings are already fully packed.

The relationship between the PSC and the EEAS is primarily distinguished by the agenda-setting role that the EEAS and the High Representative of the Union for Foreign Affairs and Security Policy and Vice-President of the European Commission (HR/VP) play in the post-Lisbon era (Maurer and Wright, 2020). According to Maurer and Wright, the EEAS has increasingly become the 'twenty-ninth member state sitting at the table', mainly because of its position as the permanent PSC chair, as described above. The fact that the PSC chair is placed under the EEAS hierarchy and charged with the responsibility to identify and forge consensus between the member states means that they are often stuck between the preferences of the HR/VP and the preferences of the majority of the group. One of the respondents described this situation as an 'inherent tension' in the role of the EEAS and consequently the PSC chair (PSC 13). As mentioned above, one of the main ways in which the EEAS influences the PSC is through setting the agenda. Since the EEAS/ PSC chair has the responsibility to set the agenda for the meetings, it has an institutional advantage in shaping the EU position compared to the member states and their representatives. As a result, some ambassadors complain that they spend more time criticizing EEAS proposals than formulating policy together (Maurer and Wright, 2020). However, Maurer and Wright contend that the member states still maintain agency and in some key dossiers, such as the Permanent Structured Cooperation (PESCO), even drive the formulation of policy (Maurer and Wright, 2020).

The actions of the HR/VP have also been consequential for how the relationship between the EEAS and the PSC has developed over the last decade. One notable example is the EU Global Strategy (EUGS) and its effects on security and defence policy. By choosing to coordinate the substance of the EUGS via an 'unorthodox system of national points of contact' instead of via the PSC or Coreper, Mogherini allegedly 'shocked' the capitals. This choice also caused concern among the PSC representatives as they were put in a position where they either had to 'take it or leave it' (Morillas, 2020, p. 237). However, the Brexit referendum in July 2016 also led to member states wanting new initiatives that signal political unity and the EU as a relevant global actor post-Brexit. The timely adoption of the EUGS just five days after the referendum, and the fact that the EUGS was a non-binding document formulated and adopted by the HR/VP, gave the EEAS and the HR/VP significant leverage in the discussions on how the strategy should be implemented; for example, on 
issues such as PESCO and the European Defence Fund (Maurer and Wright, 2020; Morillas, 2020, p. 241).

The agenda-setting impact of EEAS is also clearly apparent in the lower levels of the CFSP decision-making process, as the EEAS chairs most of the CFSP CWGs post-Lisbon. ${ }^{8}$ One of the ambassadors described this influence in the following way:

In my perspective, it was a mistake to give increasing leadership to the hands of the EEAS. Because often you see that the EEAS is driving their own agenda; their own policy according to the wishes of someone in the hierarchy, but not according to the wishes of the member states. I was working in the regional group that dealt with Asia and I saw three times in one year occasions when every member state says that the [dossier] should go in the A direction and the chair representing the EEAS says ' $O K$, OK, I hear you, we go in the B direction'. Everyone says 'no, no chair, we go in the A direction'; 'Yes, yes, yes, I hear, we go B'. This person has a specific instruction from the hierarchy. Someone in the leadership who has a specific interest. But it does not fulfill the wishes of the member states. This is not possible in the working groups which are chaired by the rotating presidency ... When you are chairing the working groups that are under the EEAS you have basically two bosses: your own hierarchy [the EEAS] who says 'you need to do this' and the member states who say 'you need to do that'. Then it depends if the chair is a strong personality and whether the person is interested in receiving another well-paid job in the EEAS ... Normally, they want to have an extension in the EEAS, have a good job. So, they tend to work with what the hierarchy says. And this prolongs the decision-making. (PSC 17)

\section{The PSC's Relation to Coreper II}

The second significant institutional relationship that impacts upon the work of the PSC is the link between the PSC and Coreper II. The relationship between the PSC and Coreper II has been described as one of 'historic competition' (Maurer and Wright, 2020). It is important to note that the representatives of Coreper II are also the heads of mission to the EU and therefore are the highest-ranking member state officials permanently based in Brussels. Although the PSC is also formally beneath Coreper II in the CFSP hierarchy, historically it has driven coordination of foreign security and defence policy, and Coreper II has taken larger ownership over the policy areas subsumed under the three other council configurations that it is responsible for preparing: the Economic and Financial Affairs Council (ECOFIN), the General Affairs Council (GAC) and the Justice and Home Affairs Council (JHA) (Howorth, 2012a, p. 442). However, this division of labour has become a bit less clear-cut over the past few years, primarily as a result of the heads of

8 RELEX, the working group responsible for sanctions against third countries, is one notable exception that is still chaired by the rotating Council Presidency. 
state and government in the European Council (EUCO) becoming much more interested in foreign policy. Since the Coreper II ambassadors usually have a tighter connection to their prime minister's office than the PSC ambassadors (PSC 23), this development has led to the EUCO and Coreper II taking a step forward, while the FAC and the PSC have become less relevant, a development described by one of the respondents in Maurer and Wright's study: '[The heads of state and government] are now engaged in the policy-making process like never before' (Maurer and Wright, 2020). One reason for this newfound interest in foreign policy in the EUCO is the increasingly cross-cutting nature of some of the most pressing issues on the agenda, such as migration. This, according to Maurer and Wright, has led to an increasing overlap between the PSC and Coreper II, which eventually has led to the PSC losing out. Given Coreper II's higher position in the hierarchy, the PSC ambassadors are simply forced to accept that they have to give up some policy areas. This view was also reflected in the interviews:

[T]he Foreign Affairs Council after the Lisbon treaty is not so powerful as it used to be, because now the centre of power is clearly within the European Council ... The Foreign Affairs Council is less important [today], that's a reality. I'm speaking against myself, but that's a reality. So, as we prepare the FAC, we have of course less importance. (PSC 7)

\section{THE IMPACT OF REFLEXIVITY ON PRACTICES AND PROCESSES OF SOCIALIZATION IN THE PSC}

Before examining the main practices of the PSC, this section briefly describes how we should understand the impact of reflexivity on the development of and efforts to sustain practices in the PSC. As noted in Chapter 4, neither socialization theory nor Bourdieuan practice theory can single-handedly explain how practices are diffused in EU foreign and security policy, as the CFSP practitioners are more conscious about their practices than what Bourdieuan practice theory would normally assume, not least as a result of the macro-level contestation that has increased over the past few years. In addition, despite frequent, intense and long-lasting interactions, the CFSP practitioners seemingly have more heterogeneous identities and interests, as well as act to a lesser degree on representational logics of action such as appropriateness and instrumental calculation, than socialization theory would normally assume. Therefore, we contend that the community-of-practice approach is more theoretically fruitful for understanding how practices are learned by the practitioners of EU foreign and security policy.

A significant part of our theoretical framework refers to how we should understand the impact of reflexivity on practices and processes of socializa- 
tion. In contrast to some of the previous international relations (IR) literature on how practices are learned, we contend that an individual's reflexivity regarding a group's practices can vary over time, most notably when they enter the group in question, and after a substantial amount of time has passed and the actor has become accustomed to the practices. In addition, a novice's consciousness regarding the group's practices should arguably increase in line with efforts made by established members of the group to persuade the novice to accept the constitutive rules of the group's practices. The reflexive character of persuasion is significant in relation to the PSC as, in comparison to other similar yet lower-ranked committees, it is within preparatory bodies such as the PSC that the clash between the member states' preferences and the aggregate position of the other member states becomes the most noticeable and decisive. In this sense, we should expect a relatively high degree of contestation and persuasion if the heterogeneity of member states is also high. If the degree of contestation within the group is high, this also implies that the group's members are relatively conscious about its practices, as they will continuously be forced to evaluate the utility and legitimacy of the practices. Therefore, the PSC is a good case to study to understand the interplay between practice and persuasion, as well as the impact that reflexivity can have on the formation of practices.

An additional consequence of accepting the notion that practices may be subject to reflexive and conscious contestation is the possibility that the members of a community of practice may also have different degrees of reflexivity about the group's practices at any given time. Such variation could essentially create a sender-recipient divide in terms of the intentionality and normativity behind different actors' actions, including the act of trying to persuade another member. In other words, an established member who has fully internalized the practices of a community, including their constitutive rules, might not reflect on whether these rules are perceived differently by different members of the community.

As diplomats serving in international institutions have different backgrounds in terms of work experience in other international organizations, the characteristics of their member states, and their national diplomatic training, there will always exist some discrepancy within a CWG or committee with respect to its members' individual positions and dispositions, as well as how the constitutive rules of the group's practices are interpreted. In combination with their respective member states' differing positions and preferences, individual representatives serving in different committees within the EU will thus sometimes be forced to evaluate whether their arguments are in line with their group's practices. It is also likely that this process is more common for some representatives than for others. For example, representatives of Western EU member states are less likely to experience situations where previously 
assumed practices, such as upholding the EU's liberal values of human rights, democracy and rule of law, are challenged by conflicting instructions from their government. However, as we have seen over the past few years, this seems to be the case for a number of representatives from member states, such as Poland and Hungary and, more recently, Greece and Italy. ${ }^{9}$ Although these situations do not always make it more difficult to find consensus among representatives, sender-recipient divides could have detrimental effects on a committee's ability to forge consensus in certain circumstances. For example, if member state governments disagree on many issues, their representatives would also be forced to have an acute sense of identifying whether a certain proposal would go against their capital's wishes. Therefore, the following section focuses on the characteristics of the practices and processes of socialization that exist within the PSC, and analyses how unequal reflexivity about the constitutive rules of the group's practices impact upon certain group members' attempts to persuade other group members.

\section{IDENTIFYING PRACTICES AND PERSUASION IN THE PSC}

This section examines the informal practices and ways in which the PSC works to forge consensus. After presenting the group's main practices, it discusses what characterizes processes of persuasion and socialization among the group's members. Finally, it explores how the sender-recipient divides in terms of the reflexivity of a practice can affect efforts of persuasion in the PSC.

\section{The Main Practices of the Group}

Previous research on the PSC and the CFSP CWGs has identified procedural norms and practices that are key for the functioning of the Council preparatory bodies. For example, in their study on socialization within CFSP CWGs, Juncos and Pomorska single out the coordination reflex ('a process of consultation and information-sharing with the rest of member states before a decision has been taken') as well as the practice of consensus-building (every representative should ultimately strive to find consensus through compromise

9 See, for example, Politico's reporting on 'Black Monday' in February 2019:

"Monday, February 4, 2019 could go down in the history books as the day a fatal blow was dealt to the EU's attempts to be taken seriously on a global stage. The cracks started showing a while ago, but on Monday it finally became crystal clear to bystanders and, perhaps, insiders, that something is going deeply wrong. Disagreement and non-action as a result of every EU country having a veto in foreign policy became the norm on Monday, not the exception.” (Eder, 2019) 
rather than hard bargaining) (Juncos and Pomorska, 2011, p. 1105). To a large degree, the existence as well as perceived importance of these practices has been upheld within the PSC; although, as alluded to above, some member states (primarily Hungary, Poland and Greece) are increasingly contesting their self-evident status by no longer adhering to these practices when discussing certain issues: chiefly human rights, the Middle East Peace Process, and external aspects of migration (PSC 5, 8, 10, 12, 13, 14, 17, 18, 19, 20, 21, 22, 23). Sexual and reproductive health and rights, as well as the EU's external relations to China and Russia, were also some issues mentioned as challenging when it comes to reaching consensus.

In the case of the coordination reflex, multiple representatives stated that they expected to not be surprised by what others would say during a committee meeting (PSC 5, 6, 11, 14, 18, 21, 22, 24). One representative went so far as to say that the explicit objective of their work as ambassadors is to make sure that they are not surprised during a meeting (PSC 22). Trust, honesty and a willingness to compromise were also pointed out by multiple respondents as key ingredients for forging consensus (PSC 6, 11, 14, 20, 21, 22). ${ }^{10}$ At first glance, this may seem a bit contradictory considering that some member states are increasingly contesting key principles of the EU. One respondent described the situation in the following way:

The French are also quite difficult, pretty often. But there is still a fundamental desire to try to reach a compromise, even if they [Hungary and France] sometime start terribly far out on the edges perhaps, and then slowly move a little. But most of the time, we are the ones who are forced to move much more than they are. But what is a little new with Hungary, and we have seen that sometimes from the Poles - perhaps some other country as well - is that they don't really care about [not] reaching a solution. (PSC 23)

In other words, the group's overarching willingness to reach consensus through compromise is still perceived to be intact, even though this practice is repeatedly contested by several member states. Although a bit counterintuitive, this view seems to indicate that some practices are more resilient than is often conceived; that is, a practice may survive within a community of practice despite the explicit and conscious rejection by one or two members of that community. In line with the critique presented above and in Chapter 4, this goes against the traditional 'Bourdieuan' view of practices as exclusively non-reflexive ways of doing things (Pouliot, 2008).

Other procedural practices that were often brought up were 'pre-cooking' (that is, finding compromises before a meeting), temporarily breaking into

10 This also echoes Howorth's findings (2012a, p. 446). 
smaller side groups to discuss the issue, avoiding redundancy (that is, simply repeating what others have previously said), as well as consistently being transparent with the positions of the capitals (PSC 5, 13, 14, 17, 18, 21, 22, 25). Suspending the formal meeting by breaking into side meetings was also connected to the representatives' shared self-perception as having a unique competence to reach consensus that rises above the lowest common denominator:

It's very common to break a meeting, not only to give people, like I said before, time to speak to their capitals, but sometimes for some groups of more interested parties, to discuss in a less posturing way, I would say. Because when you are doing a speech, you are in principle saying what your capital told you to do ... That's why the masters are there; otherwise we could do it by video-conference through the capitals. (PSC 25)

Another practice often mentioned was the presumption that each representative should act as an intermediary between their capital's instructions and the group's majority position. One respondent explained how representatives would be perceived as 'less credible if they are not really trying to explain to the capitals and come back ... Explaining of the "why" is very important why they are opposed to something' (PSC 13). When asked how much leeway a PSC ambassador in general has towards their capital, another respondent noted the following: 'I will put it this way - there is one negotiation happening in Brussels and there is another one on the phone with your own capital' (PSC 15). Acting as a dual representative of a member state and the EU/PSC was perceived as a key factor in arriving at a consensus: 'You need to listen in on what the people are saying, not only your capital. To find a compromise, you need to detach yourself sometimes from what your capital is saying' (PSC 16).

\section{Persuasion}

Being a dual representative also influenced the type of persuasion practised within the PSC. Rather than trying to persuade one another, the representatives often tried to influence their capital to accept a compromise (PSC 4, 14, 18, 25): [Y] ou become the ambassador of the EU in your own capital' (PSC 20). When explaining the job description of a PSC ambassador, another argued that 'of course ... you represent the position of your country in the PSC. But equally important, and sometimes even more important, is that you basically try to sell a landing zone to your capital' (PSC 22). It is difficult to say whether this action is the result of the role-playing socialization mechanism or the normative suasion mechanism. Although the representatives were often open about being personally persuaded by the arguments of other representatives, this was also perceived as not having much influence on the actual negotiations. For example, when asked how often he would be personally persuaded 
by the arguments of his colleagues, one representative made the following admission:

Well, you mean if I'm always personally convinced that [my member state's] position is the last word of wisdom ...? Ha ha, it's quite often the case that you ... I mean, that's also part of the interest in the way of being a PSC ambassador, that you get a relatively profound understanding of where the other EU member states are coming from in their way of thinking. And of course, very often you fully understand it, and I think that is part of your arsenal that you use when you try to convince your capital to agree to a final outcome ... But yes, I'm quite frequently convinced by the arguments of colleagues, but if it's not the position that I have to represent, it doesn't help me very much. (PSC 22)

Generally, the respondents were persuaded by logical and fact-based arguments (PSC 14, 15, 21, 23, 25). However, this was more difficult for some representatives than for others:

It is much more difficult to defend something you do not necessarily believe in, but you need to present it in a way that makes it seem as if you believe in it ... Here, you don't need to convince yourself, you need to convince 27 other partners and the EEAS. That's challenging, because you need to convince them that you are convinced. (PSC 15)

This also indicates that acting in a certain way within the group, be it arguing on behalf of the group for one's capital, or delivering credible arguments, has more to do with one's standing in the group than actually trying to persuade the other representatives of the truthfulness or normative superiority of one's position. In this sense, the act of persuasion within the committee seems to be more often a practice of role-playing rather than an actual attempt of changing the beliefs of the other representatives, that is, normative suasion (see Chapter 4).

Nevertheless, the representatives made it clear that efforts of persuasion and one's overall influence and position in the group were not necessarily causally linked. For example, one of the ambassadors explained how the representatives of the Nicolaidis group, the main preparatory body to the PSC, informally rank each ambassador's influence within the committee (PSC 25). Although this respondent did not know his own place in the ranking, he was proud of the fact that his predecessor was listed as the third most influential. However, another representative believed this informal ranking was simply a 'beauty contest' and that the Nicolaidis group simply saw the PSC from a 'performance point of view' (PSC 22). This representative argued that the real sources of influence came from the representative's ability to defend a position in a room full of people with relatively rigid pre-understandings, to display that they are knowledgeable about the issue being discussed, and to accomplish all this with a light touch and humour. In other words, a representative's standing 
and influence in the committee is seemingly related to how they present their arguments more than the actual substance of their arguments.

\section{The Impact of Unequal Reflexivity Regarding a Group's Practices}

Although the previous two sections have shown that the representatives within the PSC often act on the basis of non-reflexive practices to better position themselves in the group, we should not assume, as argued above, that these practices are interpreted in the same way by the practitioner and the audience of a certain action or argument. Although one representative might perceive that a certain practice (for example, openly discussing one's position while arguing a case) is self-evident and non-contentious, other representatives might be far more conscious about the contested meanings that may arise from such a practice.

For some representatives this 'unequal' reflexivity is far more problematic, as they often find themselves at odds with their capital's position (PSC 15). In other words, in situations where one is expected to 'perform' one's instructions by declaring and arguing for them in a meeting, this practice may only be self-evident to those representatives who have instructions with which they practically always agree. Although respondent 15 did not go into detail about how this divide affected work within the committee, beyond making it more 'challenging', the belief indicates that some practices may be sustained differently than has been previously conceived, not because all members within a certain community of practice share the same non-reflexive perception of its practices, but rather because some members consciously accept the practices without protest.

Another example of unequal reflexivity regarding the group's practices is the act of arguing for the use of previous language. According to one respondent, PSC representatives are expected to follow the acquis (that is, all previous EU legislation) when negotiating a joint position, even going so far as to say that representatives are 'good' only when they uphold this principle:

Yeah, they were angry with him, because, well, he kind of said, 'voila, this is it'. And then I came in and said, 'yes, but [ambassador's name], sorry, we cannot let it go like this. I mean this is against the acquis, we have to try to find a solution' ... And then we try to with the others to find a solution, sometimes telephones to the political directors, sometimes trying to the minister ... And now he has learned that lesson, so he's a good ambassador. (PSC 20)

Although this may be considered a self-evident practice by most representatives within the PSC, the substance of the acquis is often norm-laden; for example, in regard to the EU's fundamental values and principles: peace, democracy, rule of law, international law and human rights (TEU, art. 21). 
In other words, although the practice itself lacks any normative or moral prescriptiveness, the argument for following the acquis may be interpreted by its target (the ambassador) as a conscious attempt to influence their member state's position.

A third example of the effect of unequal reflexivity within the committee is the practice of arguing for the unity of the EU. Although one representative described how there are 'always appeals to unity' within the committee, he also saw these arguments as rhetorical devices rather than substantive pleas. When asked whether arguments that appeal to unity are often used to encourage consensus, he made the following observation:

It [an argument that appeals to unity] is used, but I think, it is my personal view that it is more rhetorical than anything. I mean we prefer unity, because this is kind of a mantra that we all use when we [negotiate] ... If a thing is very sensitive and people start to bring changes to a document that will make it even harder to swallow, I might make an appeal to unity and say, 'look, this already what is possible at this stage, so let's not [open up the text]'. (PSC 25)

Although the appeal to unity is perceived by its sender as something non-contentious and devoid of normativity, this is not necessarily the case for the representatives who may want to renegotiate a text. Off the record, a representative gave an example of how one member state wanted to add a specific word to draft Council conclusions, which would lead to many other member states also wanting to renegotiate other parts of the text. In other words, arguing that the PSC should stay unified is actually about achieving something, irrespective of the content of the decision. This desire for consensus at all costs depends on the group's ability to maintain its practices; that is, the pressure to abide by how things are done in the group, rather than to engage in persuasive argumentation. Despite the fact that the representatives' reflexivity regarding the group's practices has increased as a result of increased contestation on the member state level about what they are negotiating (the substance of the negotiations), the group still values efficiency and being able to produce policy; as can be seen in the quotation presented above regarding the group's main procedural practices. In this sense, we can understand the PSC's continued ability to remain internally cohesive as a result of its members' common understanding of the value placed on being perceived as an efficient group.

This chapter has argued that communities of practice, such as the PSC, are upheld by a combination of practices and attempts at persuasion. As stated at the beginning of the chapter, we should expect a relatively high degree of contestation and attempts at persuasion if the distance of the interests between member states increases. Arguably, this has not been the case in the PSC over the last few years. While persuasion does go on within the committee, arguments about upholding certain standards of behaviour, such as avoiding 
surprises or having a general will to reach consensus through compromise, have greater impact than substantive arguments. In other words, despite some attempts to contest these practices as well as a general increase in the heterogeneity of member states' preferences, the PSC's practices have endured.

As argued in Chapter 4, one way of understanding this apparent theoretical incompatibility is by viewing practices as having constitutive rules that can be actively reflected upon and contested. In this sense, it seems reasonable to also suggest that not all members of a community of practice will always have the same perception of the prevailing practices as self-evident. Rather, some members might view a practice as self-evident, non-intentional and devoid of normative content, whereas others might view the practice worthy of contestation and reflection. To fully capture this potential outcome, this chapter has argued that it is important to theorize the conditions and effects of unequal reflexivity regarding a group's practices.

In general, the PSC can be said to have gone through major developments over the past two decades. The new relationship to the EEAS and the HR/VP, as well as the changing relationship to Coreper II and the EUCO, has meant that the PSC has had to redefine its role many times over the past years. However, although it might not still act in the 'shadow', the PSC should be seen as a crucial component of making the CFSP work despite the significant number of crises it has had to weather. As argued elsewhere, a significant factor behind this somewhat perplexing endurance should be ascribed to the committee's capacity to socialize the procedural rules and practices of the group, rather than the constitutive norms of the EU, such as the fundamental values laid out in Article 21 mentioned above (Michalski and Danielson, 2020). By primarily socializing these procedural rules - that is, focusing on the process instead of the substance of one's arguments - the PSC has been able to remain cohesive and efficient. Only time will tell whether this strategy is sustainable. 